\title{
ENDOMETRIAL STUDY IN ABNORMAL UTERINE BLEEDING FOR A PERIOD OF ONE YEAR IN A TERTIARY CARE CENTRE
}

\author{
Chamakuri Nirmala ${ }^{1}$, Seeram Satish Kumar'2, Atla Bhagyalakshmi ${ }^{3}$ \\ ${ }_{1}^{1}$ Associate Professor, Department of Obstetrics and Gynaecology, Sri Venkateswara Medical College, Tirupathi. \\ ${ }_{2}^{2}$ Senior Resident, Department of Pathology, AMC, Visakhapatnam. \\ 3 Professor and HOD, Department of Pathology, AMC, Visakhapatnam.
}

\section{ABSTRACT}

\section{BACKGROUND}

Abnormal uterine bleeding is one of the common but complicated clinical presenting symptom in gynaecology outpatient department and has a significant morbidity which interferes with the personal, family and social life of a woman.

\section{MATERIALS AND METHODS}

It is a prospective observational study conducted in the Department of Pathology, Andhra Medical College, Visakhapatnam, for a period of one year from June 2016 to May 2017. A total of 715 patients in the age group of 18 to 65 years were included in this study. Endometrial samples were obtained and histopathological examinations were conducted. All the clinical details and investigation reports were collected.

\section{RESULTS}

Out of total 715 cases, abnormal uterine bleeding (AUB) was most commonly seen in the perimenopausal age group of 41 to 50 in 314 cases (43.92\%), 556 cases (79.9\%) were due to functional causes, while the remaining 140 cases (20.1\%) showed definite endometrial pathology. Proliferative endometrium was the most common functional histology seen in 361 cases (50.48\%). Nonatypical endometrial hyperplasia was the most common pathological cause of AUB seen in 35 cases (4.89\%). Atypical endometrial hyperplasia was seen in 6 cases $(0.8 \%)$. Endometrial carcinoma was seen in 15 cases $(2.1 \%)$ with predominant age group being postmenopausal consisting of 8 cases (53.33\%) followed by 6 cases in perimenopausal age group (40\%).

\section{CONCLUSION}

Histopathology is the gold standard for studying the pattern of endometrium and identifying the different causes of abnormal endometrial bleeding.

\section{KEYWORDS}

Abnormal Uterine Bleeding, Endometrium, Endometrial Carcinoma.

HOW TO CITE THIS ARTICLE: Nirmala C, Kumar SS, Bhagyalakshmi A. Endometrial study in abnormal uterine bleeding for a period of one year in a tertiary care centre. J. Evolution Med. Dent. Sci. 2017;6(91):6390-6394, DOI: 10.14260/jemds/2017/1389

\section{BACKGROUND}

Abnormal uterine bleeding has a significant morbidity which interferes with the personal, family and social life of a woman. The abnormal bleeding can be caused by a wide variety of disorders. It may represent a normal physiological state and observation alone may be warranted. ${ }^{1}$

In women of childbearing age, abnormal uterine bleeding includes any change in menstrual period frequency or duration, or amount of flow as well as bleeding between cycles. ${ }^{2}$ In postmenopausal women, abnormal uterine bleeding includes vaginal bleeding for 12 months or more after the cessation of menses or unpredictable bleeding in postmenopausal women who have been receiving hormone therapy for 12 months or more. ${ }^{3}$

'Financial or Other Competing Interest': None.

Submission 09-11-2017, Peer Review 20-11-2017,

Acceptance 23-11-2017, Published 27-11-2017.

Corresponding Author:

Dr. Atla Bhagyalakshmi,

Professor and HOD,

Department of Pathology,

Andhra Medical College,

Visakhapatnam-530002,

Andhra Pradesh, India.

E-mail: dr.a.bhagyalaxmi@gmail.com

DOI: $10.14260 /$ jemds $/ 2017 / 1389$
It is now generally accepted that an adequate clinical examination of abdomen and pelvis and uterine curettage, hysteroscopy or at least an endometrial biopsy are essential to exclude organic disease of the uterus in perimenopausal women. 4

Endometrial biopsy or curettage could be a safe and effective diagnostic step in evaluation of abnormal uterine bleeding after ruling out medical causes. ${ }^{5}$ Endometrial sampling is the gold standard for the evaluation of endometrial neoplasias, hyperplasias, metaplasias, pill induced and functional endometrial abnormalities. ${ }^{6}$

The study was done to evaluate endometrial histopathology for identifying the different causes of abnormal endometrial bleeding, to observe their incidence in different age groups and to compare the histopathological findings between the reproductive age group, perimenopausal and postmenopausal bleeding.

\section{MATERIALS AND METHODS}

The present study is a prospective observational study conducted for a period of one year in the Department of Pathology, Andhra Medical College, Visakhapatnam, from June 2016 to May 2017. A total of 715 patients in the age group of 18 to 65 years were included in this study.

Menstrual irregularities like heavy menstrual bleeding, breakthrough bleeding for a period of more than 3 months and intermenstrual bleeding were the presenting symptoms 
in these patients. Complications of pregnancy (like abortions, tubal pregnancies, molar pregnancies and rupture uterus), leiomyoma, adenomyosis and clinically diagnosed cases of local lesions like carcinoma cervix were excluded in the study.

Endometrial samples were obtained by biopsy, fractional curettage, dilatation and curettage and from the endometrium of hysterectomy specimens were utilised for this study. Histopathological examinations were conducted on 512 dilatation and curettage specimens and 203 hysterectomy specimens. All the clinical details and investigation reports were collected from the patients as per the proforma.

The material obtained was fixed in $10 \%$ Formalin followed by standard grossing techniques. The samples obtained by dilatation and curettage were all embedded. In hysterectomy specimens, representative areas were taken and processed. Multiple bits were given wherever necessary. Multiple sections were studied after staining with Haematoxylin and Eosin. Final diagnosis was made by thorough light microscopic examination.

\section{RESULTS}

A total of 715 patients in the age group of 18 to 65 years from patients with abnormal uterine bleeding (AUB) were analysed. The mean age was 47 years. Abnormal uterine bleeding was most commonly seen in 41 to 50 years' age group in 314 cases (43.92\%) followed by 51 - 60 years' age group in 111 cases $(15.52 \%)$ (Table 1$)$.

Most of the patients were predominantly multipara- 560 cases $(78.32 \%)$ followed by primipara- 107 cases $(14.96 \%)$, nullipara- 33 cases (4.61\%) and grand multipara 15 cases (2.09\%).

According to age group wise distribution into reproductive, perimenopausal and postmenopausal groups a total of 314 patients (43.92\%) presenting with AUB were seen predominantly in the perimenopausal age group (41 50 years) followed by 257 patients $(35.94 \%)$ in the reproductive age group (18 - 40 years) and 144 patients $(20.14 \%$ ) in postmenopausal age group (> 50 years) (Table 2).

The cause of AUB could be determined in only 696 out of 715 endometrial biopsies, as 19 biopsy specimens were inadequate for evaluation. Of the remaining 696 cases, 556 (79.9\%) were due to functional causes as no organic pathology was found, while the remaining 140 cases $(20.1 \%)$ showed definite endometrial pathology (Table 3).

Out of the 556 functional cases of AUB, proliferative endometrium was the most common seen in 361 cases $(50.48 \%)$ followed by secretory endometrium seen in 175 cases $(24.47 \%)$. This was followed by $20(2.7 \%)$ cases of disordered proliferative endometrium. Histopathological examination of the endometrium showed various histological patterns in AUB.

Non-atypical endometrial hyperplasia was the most common pathological cause of AUB seen in 35 cases (4.89\%) with predominant age group being perimenopausal consisting of 19 cases (54.28\%) followed by postmenopausal age group in 12 cases (34.28\%) (Fig. 1, 2). Atypical endometrial hyperplasia was seen in 6 cases $(0.8 \%)$, out of which 4 cases $(66.67 \%)$ were seen in perimenopausal age group and 2 cases (33.33\%) in postmenopausal age group
(Fig. 3, 4). Endometrial carcinoma was seen in 15 cases (2.1\%) with predominant age group being postmenopausal consisting of 8 cases $(53.33 \%$ ) (Fig. 5, 6) followed by 6 cases in perimenopausal age group (40\%) (Fig. 7, 8). One case of endometrial carcinoma was seen in reproductive age group in a 39-year-old female patient (Table 4).

\begin{tabular}{|c|c|c|}
\hline Age Group & Number of Cases & Percentage \\
\hline$<20$ years & 52 & 7.27 \\
\hline 21-30 years & 98 & 13.71 \\
\hline $31-40$ years & 107 & 14.96 \\
\hline $41-50$ years & 314 & 43.92 \\
\hline 51-60 years & 111 & 15.52 \\
\hline$>60$ years & 33 & 4.61 \\
\hline Total & 715 & 100 \\
\hline
\end{tabular}

\begin{tabular}{|c|c|c|}
\hline Age Group (Years) & Total & $\%$ \\
\hline 18 - 40 years (reproductive) & 257 & 35.94 \\
\hline $41-50$ years (perimenopausal) & 314 & 43.92 \\
\hline$>50$ years (postmenopausal) & 144 & 20.14 \\
\hline Total & 715 & 100 \\
\hline \multicolumn{3}{|c|}{ Table 2. Age Group Distribution of Cases } \\
\hline
\end{tabular}

\begin{tabular}{|c|c|c|}
\hline Cause & Total & $\%$ \\
\hline Functional causes & 556 & 79.9 \\
\hline Organic lesions & 140 & 20.1 \\
\hline Total & 696 & 100 \\
\hline
\end{tabular}

\begin{tabular}{|c|c|c|c|c|}
\hline $\begin{array}{c}\text { Histopathological } \\
\text { Diagnosis }\end{array}$ & $\begin{array}{l}18-40 \\
\text { Years }\end{array}$ & $\begin{array}{l}41-50 \\
\text { Years }\end{array}$ & $\begin{array}{l}>50 \\
\text { Years }\end{array}$ & Total \\
\hline Proliferative & 166 & 146 & 49 & 361 \\
\hline Secretory & 52 & 89 & 34 & 175 \\
\hline $\begin{array}{c}\text { Disordered } \\
\text { proliferative } \\
\text { endometrium }\end{array}$ & 12 & 4 & 4 & 20 \\
\hline Atrophic & - & 10 & 20 & 30 \\
\hline Chronic endometritis & 3 & 12 & 2 & 17 \\
\hline Pill endometrium & 10 & 3 & 1 & 14 \\
\hline Unsatisfactory & 5 & 10 & 4 & 19 \\
\hline Endometrial polyp & 4 & 11 & 8 & 23 \\
\hline $\begin{array}{l}\text { Non-atypical } \\
\text { endometrial } \\
\text { hyperplasia }\end{array}$ & 4 & 19 & 12 & 35 \\
\hline $\begin{array}{c}\text { Atypical endometrial } \\
\text { hyperplasia }\end{array}$ & - & 4 & 2 & 6 \\
\hline $\begin{array}{l}\text { Endometrial } \\
\text { carcinoma }\end{array}$ & 1 & 6 & 8 & 15 \\
\hline Total & 257 & 314 & 144 & 715 \\
\hline
\end{tabular}

\begin{tabular}{|c|c|}
\hline Study & Percentage \\
\hline Vaidya et al7 & $10.92 \%$ \\
\hline Abdullah et al 8 & $9.1 \%$ \\
\hline Gredmark et al $^{9}$ & $10 \%$ \\
\hline Baral et al 10 & $18.3 \%$ \\
\hline Muzaffar et al 11 & $24.7 \%$ \\
\hline Dadhania B et al ${ }^{12}$ & $25 \%$ \\
\hline Present Study & $29.28 \%$ \\
\hline \multicolumn{2}{|c|}{$\begin{array}{c}\text { Table 5. Comparison of Incidence of Hyperplasia with } \\
\text { Other Studies }\end{array}$} \\
\hline
\end{tabular}




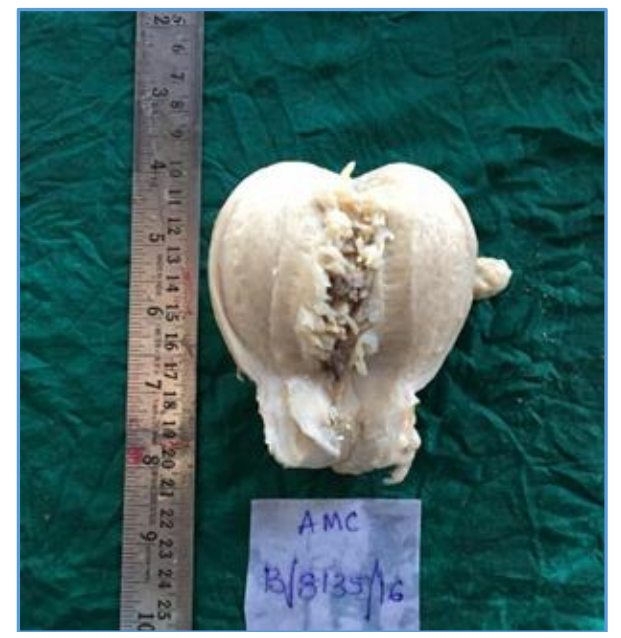

Figure 1. Gross Photograph of Hysterectomy Specimen showing Polypoidal Growth Diagnosed as Endometrial Hyperplasia on Microscopy

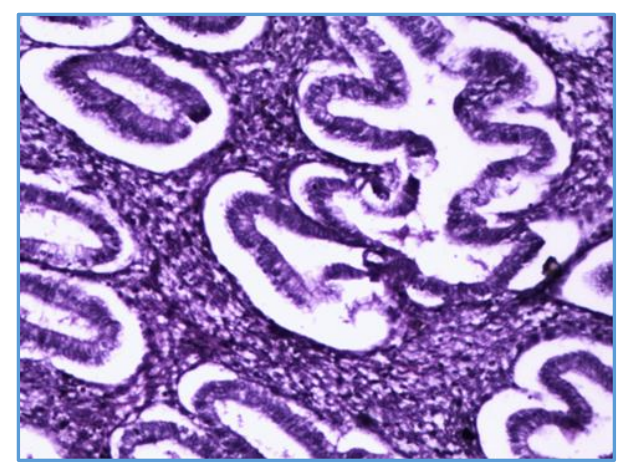

Figure 2. Photomicrograph of Non-Atypical Endometrial Hyperplasia (H and $E$ - 100x)

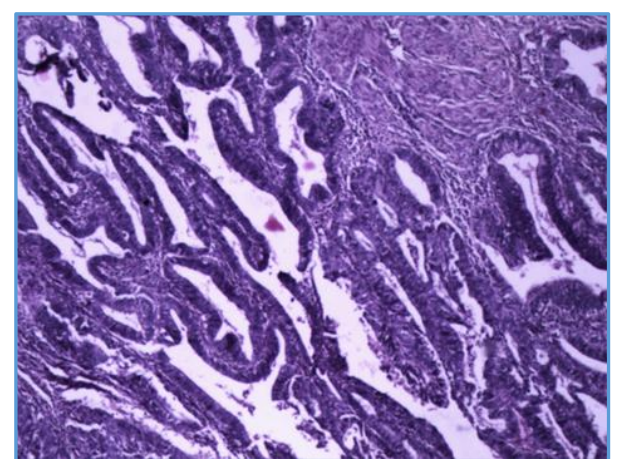

Figure 3. Photomicrograph of Atypical Endometrial Hyperplasia Scanner View (H and E - 40x)

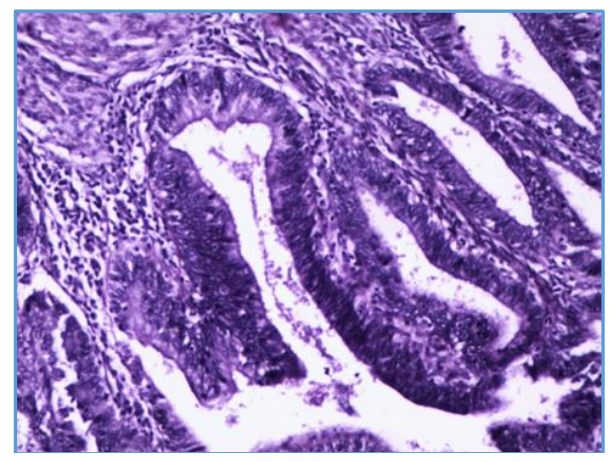

Figure 4. Photomicrograph of Atypical Endometrial Hyperplasia (H and E - 100x)

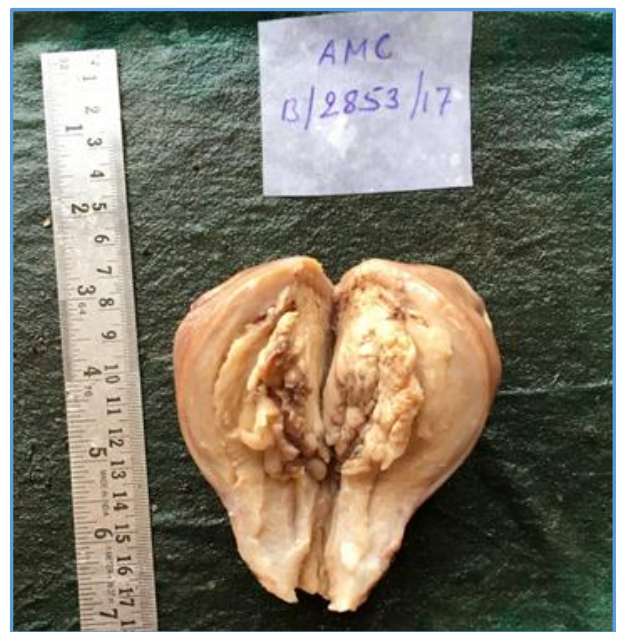

Figure 5. Gross Photograph of Endometrial Carcinoma

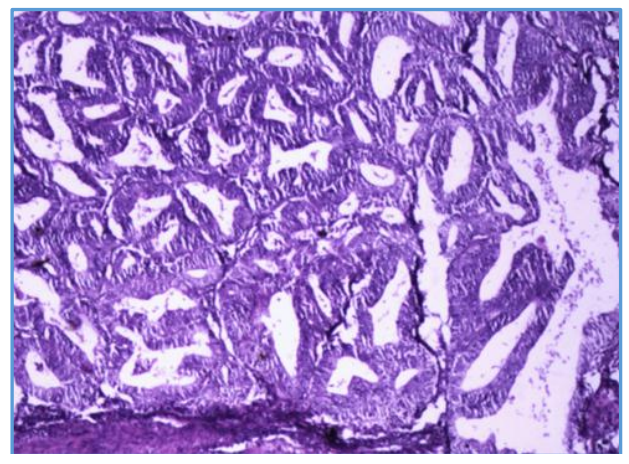

Figure 6. Photomicrograph of Endometrial Carcinoma with Back to Back Arrangement of Glands and Enlarged Hyperchromatic Nuclei (H and E - 40x)

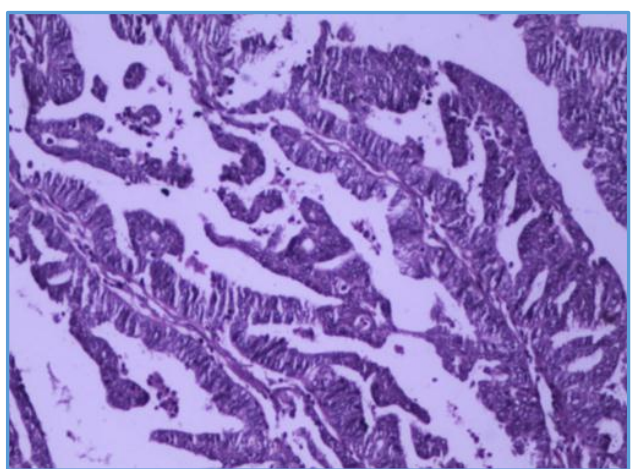

Figure 7. Photomicrograph of Serous Endometrial Carcinoma (H and E - 100x)

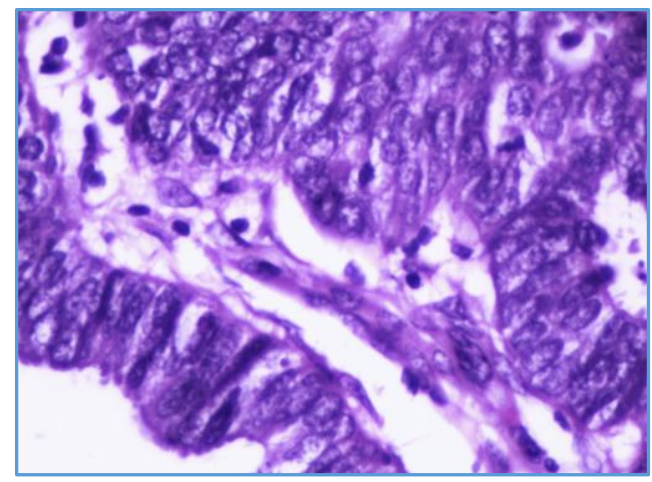

Figure 8. Photomicrograph of Serous Endometrial Carcinoma (H and E - 400x) 


\section{DISCUSSION}

Abnormal uterine bleeding is a commonly encountered gynaecological problem. ${ }^{13}$ In the present study, the commonest age group presenting with abnormal uterine bleeding was perimenopausal age group of 41 - 50 years consisting of 314 patients (43.92\%). A similar incidence was seen in endometrial studies by Yusuf et $\mathrm{al}^{14}$ and Muzaffar et al. ${ }^{11}$

The reason for increased incidence of abnormal uterine bleeding in this age group ( 41 - 50 years) may be due to the fact that these patients are in their climacteric period. As women approach menopause, cycles shorten and often become intermittently anovulatory due to a decline in the number of ovarian follicles and the estradiol level. ${ }^{5}$

In the present study, the incidence of AUB above 50 years was lower as compared to those between 41 and 50 years; 144 patients $(20.14 \%)$ were seen in the postmenopausal age group. The reason for this finding may be due to the fact that the patients were evaluated much earlier and treated appropriately, thereby decreasing the incidence in later age group. ${ }^{5}$

In the present study, abnormal uterine bleeding was predominantly seen in multipara which is comparable to those observed by Acharyaveena et al. ${ }^{15}$

Various patterns ranging from physiological to pathological lesions of the endometrium were seen on histopathological examination. In the present study, the cause of AUB could be determined in only 696 out of 715 endometrial biopsies, as 19 biopsy specimens were inadequate for evaluation; 556 (79.9\%) cases were due to functional causes. Proliferative and secretory endometrium were the two most common histopathological patterns, which were seen in all the three age groups.

Out of the 556 functional cases of AUB, proliferative endometrium was the most common seen in 361 cases (50.48\%) followed by secretory endometrium seen in 175 cases $(24.47 \%)$. Similar observation was seen in studies by Abdullah et $\mathrm{al}^{8}$ and Vaidya et al. ${ }^{7}$

In about $25 \%$ of the patients, the abnormal bleeding is the result of a well-defined organic abnormality. ${ }^{16}$ In the present study organic cause of AUB was determined in 140 cases (20.1\%), which is consistent with Ara et al17 (21.73\%), Vaidya et al ${ }^{7}(19 \%)$ and Moghal et al 18 (22.5\%).

Endometrial hyperplasias are among the most commonly over-diagnosed lesions in diagnostic surgical pathology. It is important for the pathologist to differentiate the spectrum of hyperplasias, not only from its other forms and from adenocarcinoma but also from a large number of other appearances of the endometrium, most of which are not considered hyperplastic. ${ }^{19}$

In the present study endometrial hyperplasia was the most common organic cause of AUB, which was seen in 41 (29.28\%) cases out of 140 cases. Similar data was seen in Dadhania B et $\mathrm{al}^{12}$ and Muzaffar et $\mathrm{al}^{11}$ study. Lower incidence was seen in Vaidya et al, ${ }^{7}$ Abdullah et al, ${ }^{8}$ Gredmark et al $^{9}$ and Baral et $\mathrm{al}^{10}$ studies (Table 5). The incidence of hyperplasia was also similar in the perimenopausal age group comparative to the data in these above studies.

In the present study, out of 41 cases of endometrial hyperplasias 35 were non-atypical and 6 were atypical. The most current World Health Organisation (WHO) classification recommends classification of endometrial hyperplasia collapsing the four categories into two major categories: Nonatypical hyperplasia and atypical hyperplasia (also referred to as endometrial intraepithelial neoplasia). ${ }^{20}$

Currently, atypical hyperplasia is managed by hysterectomy or in young women who desire fertility, a trial of progestin therapy and close followup. ${ }^{20}$ So, it is of utmost importance for the pathologist to differentiate hyperplasias without atypia and with atypia as the treatment of choice differs in these two conditions.

In the present study out of 30 cases of atrophic endometrium (4.1\%), most common age group was seen predominantly in the 51 - 60 years' age group consisting of 20 cases $(66.67 \%)$. The incidence is slightly lower when compared with study by Gredmark et al. The exact cause of bleeding from the atrophic endometrium is not known. It is postulated to be due to anatomic vascular variations or local abnormal haemostatic mechanisms. Thin walled veins, superficial to the expanding cystic glands make the vessel vulnerable to injury. ${ }^{5}$

In the present study, out of 23 cases (3.2\%) of benign endometrial polyps predominant age group was seen in 41 50 years' age group consisting of 11 cases (47.82\%), which was comparable to study of Doraiswami et al. ${ }^{5}$ Lower incidence of the endometrial polyps in the younger age group may be attributed to a possible spontaneous regression mechanism, which is characteristic of the cycling endometrium in reproductive age group. ${ }^{5}$

In the present study, chronic endometritis was observed in 17 cases $(23.77 \%)$. Patients with chronic endometritis can present with AUB, pelvic pain and infertility. This condition needs to be diagnosed, because with specific treatment endometrium starts functioning normally. ${ }^{5}$

Diagnostic problems still exist at both the lower end (complex hyperplasia without atypia versus atypical complex hyperplasia) and the upper end (focal low-grade endometrioid adenocarcinoma versus a more extensive or higher-grade adenocarcinoma) of the endometrial intraepithelial neoplasia spectrum. ${ }^{19}$

In the present study, endometrial carcinoma was seen in 15 cases (2.1\%) with predominant age group being postmenopausal ( $>50$ years) consisting of 8 cases $(53.33 \%$ ) followed by perimenopausal age group (41 - 50 years) consisting of 6 cases (40\%). The result of this study was comparable with Yusuf et al ${ }^{14}$ and Escoffery et al ${ }^{21}$ study.

The incidence of endometrial hyperplasia and endometrial carcinoma were more common in the perimenopausal and postmenopausal women. Hence, it is important to evaluate the histopathology of the endometrium in women of these age groups presenting with abnormal uterine bleeding to rule out possibility of pre-neoplastic condition or malignancy. 7

\section{CONCLUSION}

The pathology of abnormal uterine bleeding with endometrial cause is age related. A major diagnostic tool in evaluation of abnormal uterine bleeding is the histopathological examination of endometrial biopsy and a specific diagnosis could help the clinician to plan therapy for successful management of abnormal uterine bleeding.

The morphology, histological grading and invasion of the tumours can be made out only with histopathological study. Histopathology is the gold standard for studying the pattern 
of endometrium and identifying the different causes of abnormal endometrial bleeding.

\section{REFERENCES}

[1] Dangal G. A study of endometrium of patients with abnormal uterine bleeding at Chitwan Valley. Kathmandu Univ Med J 2003;1(2):110-2.

[2] Livingstone M, Fraser IS. Mechanisms of abnormal uterine bleeding. Hum Reprod Update 2002;8(1):60-7.

[3] Lethaby A, Farquhar C, Sarkis A, et al. Hormone replacement therapy in postmenopausal women: endometrial hyperplasia and irregular bleeding. Cochrane Database Syst Rev 2000;(2):CD000402.

[4] Davey DA. Dysfunctional uterine bleeding. In: Whit Field CR, (eds). Dewhurst's textbook of obstetrics and gynaecology for postgraduates. Glasgow, Blackwell Science, 1997:590-6084.

[5] Doraiswami S, Johnson T, Rao S, et al. Study of endometrial pathology in abnormal uterine bleeding. J Obstet Gynecol India 2011;61(4):426-30.

[6] ACOG Committee on Practice Bulletins--Gynecology. American College of Obstetricians and Gynecologists. ACOG practice bulletin: management of anovulatory bleeding. Int J Gynaecol Obstet 2001;72(3):263-71.

[7] Vaidya S, Lakhey M, Vaidya S, et al. Histopathological pattern of abnormal uterine bleeding in endometrial biopsies. Nepal Med Coll J 2013;15(1):74-7.

[8] Abdullah LS, Bondagji NS. Histopathological pattern of endometrial sampling performed for abnormal uterine bleeding. Bahrain Med Bull 2011;33(4):1-6.

[9] Gredmark T, Kvint S, Havel G, et al. Histopathological findings in women with postmenopausal bleeding. $\mathrm{Br} \mathrm{J}$ Obstet Gynaecol 1995;102(2):133-6.

[10] Baral R, Pudasaini S. Histopathological pattern of endometrial samples in abnormal uterine bleeding. J Pathol Nepal 2011;1(1):13-6.
[11] Muzaffar M, Akhtar KA, Yasmin S, et al. Menstrual irregularities with excessive blood loss: a clinicopathologic correlation. J Pak Med Assoc 2005;55(11):486-9.

[12] Dadhania B, Dhruva G, Agravat A, et al. Histopathological study of endometrium in dysfunctional uterine bleeding. Int J Res Med 2013;2(1):20-4.

[13] Nicholson WK, Ellison SA, Grason H, et al. Patterns of ambulatory care use for gynecological conditions: a national study. Am J Obstet Gynecol 2001;184(4):52330 .

[14] Yusuf NW, Nadeem R, Yusuf AW, et al. Dysfunctional uterine bleeding. A retrospective clinicopathological study over 2 years. Pak J Obstet Gynaecol 1996;9:2730 .

[15] Veena A, Seema M, Anitha R. Evaluation of dysfunctional uterine bleeding by TVS: hysteroscopy and histopathology. J Obstet Gynecol 2003;53(2):1707.

[16] Brenner PF. Differential diagnosis of abnormal uterine bleeding. Am J Obstet Gynecol 1996;175(3 Pt 2):766-9.

[17] Ara S, Roohi M. Abnormal uterine bleeding; histopathological diagnosis by conventional dilatation and curettage. Prof Med J 2011;18:587-91.

[18] Moghal N. Diagnostic value of endometrial curettage in abnormal uterine bleeding - a histopathological study. J Pak Med Assoc 1997;47(12):295-9.

[19] Silverberg SG. Problems in the differential diagnosis of endometrial hyperplasia and carcinoma. Mod Pathol 2000;13(3):309-27.

[20] Ellenson LH. The female genital tract. In: Robbins and Cotran pathological basis of disease. $9^{\text {th }}$ edn. Philadelphia: Saunders; 2014:1141-78.

[21] Escoffery CT, Blake GO, Sargenat LA. Histopathological findingsin women with postmenopausal bleeding in Jamaica. West Indian Med J 2002;51(4):232-5. 